\title{
Estudios Cromosómicos en Lactantes con Desnutrición Calórico Proteica Severa
}

\author{
Dres. Regina Moreno A. ${ }^{(1)}$ T.M.; Bianca Curotto L. ${ }^{(1)}$ T.M.; Christa Seebach B. ${ }^{(1)}$, Dr. Yves Lacassie . $^{(1)(2)}$
}

\section{Chromosomal Studies in Severe Protein Calorie Malnutrition}

\begin{abstract}
The effect of severe protein calorie malnutrition as an etiological factor of structural chromosome abnormaiities is still controversial. Lack of consensus could be explained by the heterogeneity of the climical types of malnutrition, and/or adverse environmental factors frecuently associated with this state.

We studied 5 infants with severe chronic protein calorie malnutrition and 5 normal controls. We required no history of prematurity or perinatal problems. These childsen had no antecedent of infections, nor had been exposed to drugs or radiation for the last 30 days.

In the chromosomes of these infants we determined the frecuency of sister chromatid exchanges, structural abnormalities and polimorphisms. No significant differences were found between the two eroups studied.

Our data do not support that protein calorie malnutrition "per se" produces chromosomal damage.
\end{abstract}

\section{INTRODUCCION}

La desnutrición calórico-proteica (DCP) produciría aberraciones cromosómicas, tanto en humanos $(1,2,3)$ como en animales de experimentación $(4,5)$. Sin embargo, otros estudios no las han demostrado $(6,7)$, o plantean la duda si realmente se deberían a la desnutrición "per se", o más bien a factores intercurrentes, tales como infecciones, tratamientos con drogas, exposición a radiaciones diagnósticas o carencias especificas de metionina, vitamina B-12 o folato, frecuentes en los nifios desnutridos y que podrían actuar como agentes mutagénicos $(7,8)$.

Siendo la desnutrición un problema relevante en paises en vías de desarrollo como el nuestro, nos pareció importante estudiar las posibles alteraciones cromosómicas, especialmente el Intercambio de Cromátides Hermanas (ICH), técnica de mayor sensibilidad para detectar inestabilidad

1 Unidad de Genética, INTA, Universidad de Chile.

2 Estudio financiado por Grant No B-687-791 y 801 . Servicio de Desamollo Científico, Artístico y de Cooperación Internacional. Universidad de Chile. cromosómica $(9,11)$, en lactantes con DCP severa primaria, sin factores intercurrentes que pudieran explicar posibles alteraciones.

\section{MATERIAL Y METODO}

Se estudiaron 5 lactantes hospitalizados en los Centros Cerrados de Recuperación Nutricional (CCRN) de la Corporación para la Nutrición Infantil (CONIN), por DCP severa (marasmo) de origen primario, sin antecedentes de premature 2 , patología perinatal, malformaciones congénitas, ni de morbilidad ingesta de antibióticos u otras drogas, o exposición a radiaciones diagnósticas en los 30 días previo a su intemación. Se completó una ficha con la información pertinente a cada nif̂́ $\mathrm{y}$ se tomó una muestra de sangre periférica en los primeros días de su ingreso al centro, antes que se iniciara su proceso recuperacional.

Como controles se estudiaron 5 lactantes eutróficos que concurrían a control de niño sano a un policlínico del sector, de condiciones y edades semejantes. Las características generales $y$ antropométricas de la población estudiada se presentan en la Tabla I. 
Tabla 1.

Caracteristicas Generales y Antrop ométricas de la Población Fstudiada

Desnutridos:

\begin{tabular}{|c|c|c|c|c|c|c|}
\hline Caso & Sexo & $\begin{array}{c}\text { Edad } \\
\text { (meses) }\end{array}$ & $\begin{array}{l}\text { Pcso } \\
(G r)\end{array}$ & $\begin{array}{l}\text { Talla } \\
\text { (Cm.) }\end{array}$ & $\% \mathrm{P} / \mathrm{L}$ & $\% \mathrm{P} !$ \\
\hline I & $M$ & 7 & 5.300 & 62 & $65(3)$ & $92(1)$ \\
\hline 2 & $\mathbf{M}$ & 6 & 5.200 & 57.8 & $68(3)$ & $102(\mathrm{~N})$ \\
\hline 3 & $\mathbf{M}$ & 4 & 4.870 & 59.4 & $75(2)$ & $86(1)$ \\
\hline 4 & $F$ & 4 & 4.050 & 55 & $67(2)$ & $91(1)$ \\
\hline 5 & $F$ & 9 & 5.040 & 60 & $60(3)$ & $88(1)$ \\
\hline
\end{tabular}

Controles (Eutróficos):

\begin{tabular}{rrrrrrr}
\hline 1 & $M$ & 3 & 6.600 & 63.5 & 93 & 97 \\
2 & $M$ & 10 & 9.800 & 71 & 106 & 109 \\
3 & $M$ & 7 & 7.630 & 67 & 94 & 98 \\
4 & $M$ & 10 & 10.000 & 73 & 108 & 105 \\
5 & F & 10 & 8.820 & 31.5 & 101 & 97 \\
\hline
\end{tabular}

A cada niño se le realizaron 2 cultivos paralelos de linfocitos en medio TC 199 (Difco) durante 72 horas. Uno con técnica estandard para analizar polimorfismo y alteraciones estructurales, median- te bandeos $\mathrm{C}, \mathrm{R}$ y $\mathrm{G}$; el otro, para el anáfisis de ICH, fue cultivado en oscuridad, agregándose BrdU $(10 \mathrm{ug} / \mathrm{ml})$ al inicio del cultivo. La cosecha se realizó en la forma habitual y las preparaciones fueron sometidas a tinción diferencial, según el procedimiento de Korenberg y Freedlender 12). EI análisis de $\mathrm{ICH}$ fue realizado en un promedio de 30 metafases por sujeto.

Todos los análisis cromosómicos fueron realizados por 2 investigadores, en forma independiente, obteniéndose una alta correlación entre sus observaciones. En los casos de discrepancias, un tercer investigador dirimía.

\section{RESULTADOS}

El anălisis cromosómico con los bandeos $G, R$ y $C$ no demostró diferencias significativas de alteraciones estructurales, polimorfismo, "gaps" o fracturas entre los lactantes desnutridos y el grupo control. Los resultados obtenidos en el recuento de ICH se muestran en la Tabla 2. En los niños desnutridos se obtuvo un promedio de $10.5 \mathrm{ICH}$; cel. Con DS de 3.79 y en los controles un promedio de $10.7 \mathrm{ICH} /$ cel con DS de 4.46. Esta diferencia no es significativa, aplicando el Test de Student (T:-.4316l, $\mathrm{p}>0.20$ ).

Tabla 2

Intercambio de Cromatides Hermanas

\begin{tabular}{ccccccc}
\hline & & Desnutridos & & & \multicolumn{2}{c}{ Controles } \\
\hline Caso No & ICH Total & X ICH/CEL & DS & ICH Total & X ICH/CEL & DS \\
\hline 1 & 229 & 10.9 & 2.37 & 215 & 7.4 & 2.52 \\
2 & 428 & 14.7 & 3.96 & 257 & 8.5 & 3.31 \\
3 & 319 & 10.2 & 2.38 & 317 & 10.5 & 3.22 \\
4 & 218 & 8.7 & 2.83 & 486 & 16.2 & 4.15 \\
5 & 255 & 8.2 & 2.83 & 311 & 11.1 & 2.84 \\
\hline TOTAL & 1.449 & $10.5^{*}$ & 3.79 & 1.586 & $10.7^{*}$ & 4.46 \\
\hline
\end{tabular}

* T:,- 43161 p $>0.20$

\section{DISCUSION}

La mayoría de los estudios en desnutridos han analizado las alteraciones estructurales cromosómicas mostrando diferencias en frecuencia y tipo de aberraciones (1,3). Estas varian desde "gaps", que son las "alteraciones espontáneas" más frecuentes encontradas en la población normal, hasta cromo- somas dicéntricos y en anillo. Hasta ahora no hay explicación para estas diferencias (3). Sin embargo, no todos los trabajos publicados en humanos han estudiado formas homogéneas de desnutrición. La mayoría mezcla marasmo y kwashiorkor $(1,3,8$, 13). Además es difícil obtener pacientes desnutridos en los cuales no influyan factores ambientales que puđieran actuar como agentes mutagénicos. 
De aquí que hasta el momento no se haya podido demostrar en forma fehaciente que la desnutrición "per se" produzca alteraciones cromosómicas en humanos.

En nuestro trabajo el análisis corriente (Giemsa estandar) y con bandeos G, C y R no demostró alteraciones estructurales.

Aunque el mecanismo de producción de JCH está aún en etapa hipotética (14), se ha comprobado que esța técnica es un indicador muy sensible para detectar efecto de agentes mutagénicos y carcinogénicos (10, 11). Nuestro estudio concuerda con el de Mutchinick (15) en cuanto a no encontrar un aumento de frecuencia de ICH en niños desnutridos. Nuestra muestra, aunque reducída, corresponde a nifios marásmicos, muy seleccionados, de acuerdo a las condiciones del estudio $y$ en los que no habtía exposición a potenciales inductores de mutación, al menos en el mes previo al estudio. Estos 5 pacientes fueron obtenidos entre 18 desnutridos estudiados, ya que por diferentes motivos se obtenían los antecedentes clínicos, familiares y otros datos relevantes, sólo después de iniciado el estudio. Además, la presencia de otras afecciones, ocultas bajo la desnutrición, no son infrecuentes (16).

$\mathrm{Si}$ bien no todos los agentes que producen rotura cromosómica producirian también aumento de ICH, de acuerdo a este estudio, la desnutrición calórica proteica crónica, no produciría ni lo uno ni lo otro.

\section{RESUMEN}

Existe controversia sobre el efecto de la desnuitrición a nivel cromosómico. La falta de consenso podria deberse a heterogeneidad de los tipos clínicos de desnutrición y/o a factores medio ambientales adversos, con frecuencia presentes en niños desnutridos. Se estudiaton los intercambios de Cromátides Hermanas (ICH), alteraciones estructurales y polimorfismos cromosómicos, utilizando diferentes técnicas de bandeo, en 5 lactantes con desnutrición calórico-proteica severa primaria (DCP), sin antecedentes de prematurez, problemas perinatales, afecciones genéticas, metabólicas, neurológicas o malformaciones ni de infecciones, drogas o radiaciones en el último mes. Como controles se estudiaron 5 lactantes eutróficos, de edad y condiciones semejantes. No hubo diferencias significativas en el número de ICH; ni en la frecuencia de álteraciones estructurales entre los dos grupos.

Nuestros resultados permiten concluir que la DCP severa "per se" no produciría alteraciones cromosómicas.

\section{AGRADECIMIENTOS}

Agradecemos a los CCRN Macul, San Miguel y Vitacura de CONIN, así como al Consultorio Santa Julia, la colaboración prestada para este estudio. Igualmente a María Teresa Segure por el análisis estadístico y a la Sra. Viola Lyon, por su excelente labor secretarial.

\section{REFERENCIAS}

1 Armendares, S., Salamanca, F., Frenk, S. Chromosome abnomalities in severe protein calorie malnutrition Nature 232: 271, 19871 .

${ }^{2}$ Gupta, R., Gupta, M., Ramdeo, I. N. : Chromosomal abnormalities in protein-calorie malnutrition. Am. J. Clín. Nuts. 30: 1974, 1977

${ }^{3}$ Betancourt. M., De in Roca, J.M., Sienz, M.E., Diaz, R. Cravioto, J,: Aberraciones cromosómicas en desnutrición proteico-calórica avanzada. Bol. Med. Hosp. Infant. (Méx.) 29: $517,1972$.

4 Sadasizan, G., Raghuram, T.C.: Chromosomal aberrations in malnutrition. Lancet 2: 574, 1973.

5 Vijayalaxmi, E.: Chromosomal aberrations in malnutrition. Metabolism 24: 1415, 1975.

"Thorburn M.J., Hutchinson, S., Alleyne, G.A.O. Chromosome abnormalities in malnourished children. Lancet 1: $591,1972$.

${ }^{7}$ Betancourt, M.: De la Roca, J.M.; Cravioto, J.: Ionising radiation and chromosomal aberrations in malnutrition. Lancet 2: $1332,1974$.

${ }^{8}$ Khouri, F.P.: McLaren, D.S. Cytogenetic studies in protein-calorie malnutrition. An. J. Hum. Genet, 25:465 1973.

${ }^{9}$ Latt. S.A.: Analysis of sister chromatid exchange and chromosome replication kinetics using BrdU-Dye Techniques. Virchows Arch. B. Cell. Path. 29: 19, 1978.

${ }^{10}$ Wolff. S.: Sister chromatid exchange. Ann. Rev. Genet. $11: 183.1977$.

${ }^{11}$ Kato, $H$., Shimada, H.: Sister chromatid exchanges induced by mitomycin $\mathrm{C}: \mathrm{A}$ new method of detecting DNA damage at chromosomal level. Mutat. Res. $28: 459,1975$

${ }^{12}$ Korenberg, J.R., Freedlende, E.F.: Giemsa technique for the detection of sister chromatid exchanges. Chromosoma 48: 355, 1974 .

${ }^{13}$ Betancaurt, M., De la Roca, J.M., Sáenz, M.E, Diaz, R., Crovioto, $J$.: Chromosome aberrations in protein-calorie malnutrition. Lancet 1: 168, 1974.

${ }^{14}$ Kato, H.: Mechanisms for sister chromatid exchanges and their relation to the production of chromosomal aberrations. Chromosoma 59:179, 1977.

${ }^{15}$ Mutchinick, O, Lisker, R., Ruz, L., Salamanca, F., Armendares, S.: Erecuency of sister chromatid exchanges in severe protein-calorie malnutrition. Ann. Genet. 22: 129, 1979.

${ }^{16}$ Lacassie, Y.. Colombo, M., López, I.: Desnutrición secundaria: Impacto de afecciones genéticas, metabólicas y ncurológicas. Rev. Chil. Ped. 51: 257, 1980. 